\title{
Tres pandemias en la Historia
}

\author{
Patricia Kreibohm ${ }^{1}$
}

Desde tiempos inmemoriales, la humanidad fue acosada por las enfermedades. Más o menos extendidas en el tiempo y en el espacio, siempre representaron una grave amenaza. Sin embargo, en todos los casos, fueron superadas.

En realidad, la aparición de epidemias se incrementó a partir del Neolítico, cuando los hombres empezaron a cultivar la tierra y a domesticar algunas especies de fauna salvaje. De hecho, este contacto más estrecho con los animales provocó la transmisión de diversos agentes patógenos, lo que configuró lo que hoy se conoce como "zoonosis". Un ejemplo concreto de los temores que generaban estos contagios son las prohibiciones establecidas por religiones como la musulmana o la judía, que impiden a sus fieles la ingesta de carne de cerdo y sus derivados. ${ }^{2}$

A lo largo del tiempo y según determinados parámetros establecidos por los especialistas, estas enfermedades generalizadas fueron categorizadas de diversas formas. Así, una epidemia es un mal que se propaga durante un tiempo determinado en un país o una región específica. Una pandemia es una epidemia que se extiende en el tiempo y en el espacio, y afecta a gran cantidad de individuos, para la que no existen ni tratamientos ni vacunas conocidos.

En este artículo, vamos a referirnos al desarrollo de tres grandes pandemias históricas: 1) la peste negra del siglo XIV en Europa, 2) las pandemias americanas durante la época de la conquista y 3 ) la gripe española de 1918.

DOI: $10.24215 / 23142766 \mathrm{e} 0100$

\footnotetext{
${ }^{1}$ Magister en Relaciones Internacionales (Universidad Nacional de Tucumán), coordinadora del Departamento de Historia de las Relaciones Internacionales del IRI-UNLP

${ }^{2}$ Una de las enfermedades más contagiadas por los cerdos es la triquinosis.
} 


\section{La peste negra del siglo XIV en Europa.}

La primera oleada de esta enfermedad se inició en 1347 y se prolongó hasta 1353. Los brotes posteriores se dieron con intervalos de diez, quince o veinte años, y se extendieron -con mayor o menor intensidad- hasta el siglo XVII.

En cuanto a los datos, los cálculos indican que la peste causó la muerte a una cifra que oscila entre 40 y 80 millones de personas, lo que representa entre el 30 y el $60 \%$ de la población europea. Asimismo, y en función de su proyección a otras regiones del mundo, los especialistas aseguran que el número total de víctimas mortales sería de 200 millones. $^{3}$

Aparentemente, la enfermedad se habría originado en China o en el centro de Asia y su llegada a Europa se habría producido en barco. En efecto, la peste fue traída por naves genovesas y los primeros registros la ubican en el puerto de Messina. Se trata de una zoonosis transmitida por ratas, cuyas pulgas estaban infectadas con la bacteria $\underline{\text { Yersinia pestis. }}$

\section{El contexto y sus efectos.}

El siglo XIV es considerado por los historiadores una etapa de crisis. Identificado como un ciclo B (Negativo), se caracterizó por el encadenamiento de diversos factores que provocaron lo que se denomina "la profunda retracción del siglo XIV". El primer eslabón de esta cadena fue un problema climático: exceso de lluvias y de frío. Esto provocó dos efectos casi inmediatos: malas cosechas y, por lo tanto, escasez de comida, lo que se tradujo en hambre o subalimentación. Sus secuelas fueron el incremento de la mortalidad y el debilitamiento del sistema inmunológico de los individuos que lograron subsistir. En estas condiciones, la propagación de la enfermedad fue vertiginosa.

Para referirnos a sus efectos, vamos a dividirlos en dos categorías: los materiales y los no materiales.

a. Aquí lo más sobresaliente fue la mortalidad masiva, que representó una verdadera catástrofe demográfica. Dicha catástrofe afectó al campo y a las ciudades por igual y redujo notablemente la mano de obra agrícola, lo cual significó la disminución sistemática del cultivo y la falta de alimento durante muchos años. ${ }^{4}$ Por otra parte, generó un empobrecimiento generalizado, provocó la dispersión de las fuerzas productivas y quebró los circuitos comerciales. Pero, además, la crisis económica también desencadenó la violencia. En esta etapa, estallaron levantamientos campesinos, saqueos, ataques y pogromos que agravaron notablemente la situación. En definitiva, y hablando en términos generales, se produjo un retroceso y un caos extraordinario que, como sostiene Pierre Vilar, aplastó a la civilización europea de la época.

b. Con respecto a los efectos no materiales, los más importantes fueron la alteración de las emociones, el miedo, la angustia y la inseguridad, así como también la desconfianza

\footnotetext{
${ }^{3}$ En este sentido, se estima que la peste llegó también a Medio Oriente, India y Rusia.

${ }^{4}$ De hecho, se calcula que, durante décadas, la superficie de bosques se recuperó entre un 15 y un $25 \%$
} 
y el escepticismo. Especialmente importantes fueron las nuevas actitudes hacia la religión y la Iglesia. De hecho, en estos tiempos afloraron el secularismo y el rechazo a la fe, pero también y de manera simultánea, diversos fanatismos y herejías.

En este contexto, surgió un nuevo género artístico que se conoce como "Ias danzas de la muerte". Se trata de una serie de manifestaciones pictóricas, artísticas y literarias que se centran en el tema de la fragilidad de la vida y en la potencia de la muerte. Esta última, representada normalmente como un esqueleto, cubierto por una capa y una capucha negra, empuña una guadaña. En todas estas obras, ella es la gran protagonista que siempre triunfa segando vidas; es la gran igualadora que se lleva al pobre campesino y a sus hijos, pero también al príncipe y al cardenal. El mensaje de estas danzas incita al pueblo a disfrutar de los placeres terrenales pues -más tarde o más temprano- todo habrá de ser macabro, corrupto y tenebroso.

Paulatinamente y ya en el mediano plazo, se fueron abandonando las formas tradicionales, se profundizó el individualismo e hicieron su aparición nuevas cosmovisiones que evidenciaron la crisis del modelo feudal. De hecho, ya a finales de este siglo, surgieron las primeras expresiones culturales que marcarían un cambio radical: el Humanismo, el Renacimiento y la Reforma Protestante. Según los especialistas en estos temas, a partir de fines del XIV se gestó una nueva sensibilidad colectiva que se manifestó claramente en el arte, la música y la literatura. Nuevos temas -como el hombre y la naturaleza- captaron la atención de los artistas que empezaron a abrazar lo terreno desde diversas perspectivas, creando lo que A. Hauser ha denominado "un nuevo sistema cultural, centrado en el eje antropológico".

\section{El gran colapso americano.}

La primera oleada apareció en 1519 y se prolongó hasta 1526. La segunda se dio desde 1545 hasta 1576. De allí en adelante, distintos brotes afectaron al continente americano hasta comienzos del siglo XVIII.

Ahora bien, en este caso, es necesario realizar dos aclaraciones. La primera es que las pestes afectaron especialmente a lo que hoy conocemos como Latinoamérica y la segunda, que no fue una sola enfermedad la responsable de los decesos; por el contrario, fueron varios los males que se desataron en nuestras tierras. Los más importantes son: la viruela, las infecciones bronco-pulmonares y las fiebres hemorrágicas y entéricas.

También es necesario señalar que este tema es sumamente polémico pues, durante mucho tiempo, enfrentó a los historiadores. De un lado se sitúan los que adjudican la tremenda mortalidad americana a los malos tratos y a la violencia que sufrieron los indios por parte de los conquistadores. Del otro, están los que -sin negar la existencia de dichos abusos- creen que fueron las enfermedades las que generaron la hecatombe. En la actualidad, se han acercado un poco más las posiciones y se ha concluido que, efectivamente, las pestes fueron lo más relevante, pero indudablemente los padecimientos físicos y psicológicos sufridos por los pobladores contribuyeron notablemente a disminuir sus defensas y a convertirlos en víctimas fáciles para la enfermedad. 
En cuanto a las cifras, son realmente escalofriantes pues indican que las pandemias mataron al $90 \%$ de la población aborigen. De hecho, de los 90 millones de habitantes que habitaban la América precolombina, más de 80 murieron a causa de éstas.

Con respecto a su origen, está claro que fueron traídas por los europeos quienes, en la gran mayoría de los casos, tenían defensas inmunológicas suficientes como para no padecerlas y si las contraían, en general, no los mataba.

\section{El contexto y sus efectos.}

Como se sabe, cuando llegaron los españoles, en América existían diversas civilizaciones, cada una de las cuales tenía distintos grados de desarrollo. Sin embargo, los historiadores concuerdan en señalar dos cuestiones que eran comunes a todas ellas. La primera es que sus dietas estaban basadas en productos vegetales (maíz), pero eran pobres en proteínas y grasas (comían muy poca carne y lácteos), lo cual no contribuía a fortalecer sus defensas. La segunda es que América era un continente con muy poca comunicación; una situación que impidió o disminuyó notablemente la capacidad de sus pobladores para enterarse de lo que pasaba en otras regiones y buscar formas más adecuadas para protegerse. ${ }^{5} \mathrm{En}$ cuanto a sus efectos, los dividiremos también en materiales y no-materiales.

La hecatombe americana no sólo fue dramática por el número de víctimas, sino también por el poco tiempo en el que se produjo este colapso. Para la mayoría de los autores, en 60 años sólo quedó con vida entre el 5 y el 7 \% de la población originaria. Por otra parte, es indudable que la masiva mortalidad contribuyó notablemente a que se acelerara el proceso de conquista. La disolución de los esquemas de autoridad local fueron sumamente veloces y esto desencadenó la dispersión de las comunidades y la desarticulación de los sistemas económicos, todo lo cual derivó en el advenimiento de hambrunas y de violencia. De hecho, las guerras civiles y los levantamientos aborígenes generaron un círculo vicioso casi interminable de más hambre y más violencia.

Una vez más, en este caso, los sentimientos colectivos fueron de angustia, miedo y zozobra. Sin embargo, la sensación de impotencia y de resentimiento frente a los nuevos dueños del poder incrementaron el abatimiento colectivo. Como señala P. Chaunu, "en esos días, los hombres de América, veían como su mundo se derrumbaba y desaparecía; cómo caían sus dioses y cómo morían los que amaban. Pero también sentían cómo se extinguían sus propias certezas, sus creencias y sus ilusiones. En este sentido, los especialistas hablan de dos reacciones muy frecuentes entre los americanos: por un lado, el rechazo a la vida y, por otro, la búsqueda desesperada de seguridad y protección". ${ }^{6}$

"Es indudable que las cocoliztlis contribuyeron de manera decisiva a explicar cómo, unos cuantos miles de europeos, pudieron dominar en muy

\footnotetext{
${ }^{5}$ Hernán Cortez llegó a Méjico en 1519. Los Pizarro entraron al territorio del imperio Inca en 1532. Entre un episodio y otro habían pasado 14 años. Sin embargo, los incas fueron sorprendidos por la conquista pues no habían tenido ninguna noticia de cómo los europeos habían penetrado en el espacio americano.

${ }^{6}$ Algunos autores sostienen que ésta última actitud, contribuyó notablemente a las conversiones masivas al catolicismo.
} 
pocos años, millones y millones de kilómetros cuadrados en los que vivían otros tantos millones de personas. En efecto, fueron las pestes, las grandes aliadas de los españoles; pestes que ellos llevaban consigo sin siquiera saberlo".

\section{La gripe española de 1918.}

Esta enfermedad se inició en pleno desarrollo de la Primera Guerra Mundial (febrero/marzo de año 1918) y sus primeros registros se dieron en Fort Riley, Kansas, Estados Unidos. Se trató de una zoonosis: la influenza del tipo N1H1. En muy poco tiempo, más de 10 campamentos militares norteamericanos, se encontraban colapsados por la cantidad de infectados. La primera región a la que se extendió fue Europa y de allí, a otras áreas del globo. Duró un poco más de dos años y desapreció tan súbitamente como había llegado.

Según los datos disponibles, mató a un estimado entre 25 y 50 millones de personas, la gran mayoría de ellas jóvenes (20/40años) y saludables. Durante su desarrollo, mutó un par de veces, lo cual potenció su capacidad para contagiar.

Como dijimos, la primera oleada se inició en marzo de 1918 y afectó casi exclusivamente a las tropas norteamericanas que viajaron a Europa y a los ejércitos de los países beligerantes en el viejo continente. La segunda oleada empezó en diciembre del mismo año y sus víctimas fueron, fundamentalmente, civiles.

\section{El contexto y sus efectos.}

El año 1918 fue el último de la Primera Guerra Mundial. Una guerra que había desgastado profundamente a los países europeos y que fue, hasta ese momento, la más sangrienta de la historia. La contienda se había iniciado en julio de 1914 y tuvo distintas etapas. En el año 1917, se produjeron dos cambios importantes: a) Rusia (que integraba el bloque de los Aliados) salió de la guerra hacia fines de ese año, en virtud de la decisión del nuevo gobierno comunista que había llegado al poder en el mes de octubre, y b) los EE.UU. declararon la guerra a los imperios centrales el 6 de abril de 1917 y, a partir de entonces, se organizó el operativo de traslado de las tropas.

Para el presidente Wilson, era vital entrar a la contienda, pues la salida de Rusia ponía en riesgo el triunfo de los Aliados. Esta determinación lo condujo a tomar dos medidas concretas: enviar a sus tropas a Europa, a pesar de saber fehacientemente que estaban infectadas, y censurar todo lo posible la información disponible sobre la enfermedad. ${ }^{7}$ De hecho, muchos especialistas se refieren a ella como "la peste olvidada o la peste escondida".

Los daños provocados por esta gripe no se limitaron a las vidas humanas, sino que también se extendieron a otros ámbitos, específicamente a lo económico. En efecto, en la

\footnotetext{
${ }^{7}$ Esto provocó que se la llamara "española", pues el único país que hablaba libremente de esta epidemia era España.
} 
inmediata postguerra se desató una crisis inédita; una crisis en la que se conjugaron los estragos de la contienda, el desastre sanitario y el debilitamiento de los sistemas políticos. Al respecto, algunos autores sostienen que fue la peste la gran responsable de que la recuperación del continente se demorara tanto tiempo.

Los años de entreguerras fueron muy amargos y estuvieron fuertemente marcados por los viejos dramas de la Humanidad: el hambre, la peste y la muerte. En este periodo, los miedos, las angustias y las incertidumbres de los europeos (que creían pertenecer a la sociedad más desarrollada del planeta) fueron muy profundos y se expresaron también a través del arte, la literatura, la filosofía y la cultura en general. Tanto las Vanguardias como la vorágine de los años locos pusieron de manifiesto que todas las esferas de la vida se habían alterado. Pero lamentablemente, este no fue el final de un proceso nefasto; por el contrario, sólo fue el inicio de nuevos infiernos. 